\title{
Synergistic Effect of EG and Cloisite 15A on the Thermomechanical Properties and Thermal Conductivity of EVA/PCL Blend
}

\author{
Tebello Abel Tsotetsi ${ }^{a}$, Mokgaotsa Jonas Mochane $e^{b}$, Tshwafo Elias Motaung ${ }^{b *}$, Thandi Patricia \\ Gumede $^{a}$, Zikhona Linda Linganiso ${ }^{b}$ \\ ${ }^{a}$ Department of chemistry, University of the Free State, Qwaqwa campus, Phuthaditjhaba, Free State, \\ South Africa \\ ${ }^{b}$ Department of Chemistry, University of Zululand - UNIZULU, Kwadlangezwa, KwaZulu-Natal, South \\ Africa
}

Received: April 7, 2016; Revised: August 2, 2016; Accepted: September 8, 2016

\begin{abstract}
The purpose of this study was to investigate the synergy of expanded graphite (EG) and Cloisite $15 \mathrm{~A}(\mathrm{C} 15 \mathrm{~A})$ on the thermal conductivity and thermomechanical properties of ethylene-vinyl acetate copolymer/poly ( $\varepsilon$-caprolactone) (EVA/PCL) blend. Scanning electron microscopy (SEM) results showed that the blend had a phase separation, in which the PCL phase (appeared as droplets) was dispersed uniformly in the EVA matrix in all samples. The results from SEM and X-ray diffraction (XRD) showed that as the EG content increases, graphite sheets increase, leading to a high probability of re-stacking and poor dispersion as well, however the synergy rendered an increase in the storage modulus for the composite containing low content of EG (5phr) in both the EG and clay containing samples. The addition of EG showed a slight increase in thermal stability,but the presence of C15A decreased the onset of degradation of EVA/PCL blend. However, at high temperatures the synergistic effect of EG and C15A showed better thermal stability for EVA/PCL blend than EG alone. The addition and increase in EG content improved thermal conductivity of the EVA/PCL blend in both the clay containing and EG containing samples, however the clay-containing samples showed lower values compared to EG only.
\end{abstract}

Keywords: Cloisite 15 A, Expanded graphite, Thermal conductivity, Blends

\section{Introduction}

Blending of more than two polymers to achieve distinct properties that separate materials do not possess is one of the most applicable techniques widely practiced. Nearly all of the polymer blends are immiscible or incompatible on a molecular scale for thermodynamic reasons such as small combinatorial entropy and positive enthalpy of mixing. The effectiveness of immiscible blends is strongly influenced by phase morphology i.e. shape and size as well as the properties of each polymer component ${ }^{1-3}$. Polymer blending has the following advantages: cheap, easily processable, and distinct properties can be achieved depending on the composition and preparation methods ${ }^{4,5}$.

Biodegradable polymers receive increased attention because of their biodegradability and thermoplastic properties. Poly ( $\varepsilon$-caprolactone) $[\mathrm{PCL}]$ is popular as a biodegradable polymer because of its good mechanical properties and compatibility with varieties of the polymers. Apart from the biomedical use, it has been used as mould release agent, adhesive, and pigment dispersant, synthetic wood dressing as a replacement for plaster of Paris in splints and as a material for orthopedic casts $^{6}$. On the other hand, ethylene-vinyl acetate copolymer (EVA) is a commodity plastic material resulting from the copolymerization of ethylene and vinyl acetate (VAc)

*e-mail: motaungt@unizulu.ac.za comonomers. VAc units in ethylene-vinyl acetate copolymer are randomly dispersed in the backbone, which give EVA excellent properties such as flexibility, fracture toughness, light-transmission properties, and adhesion to other organic/ inorganic materials ${ }^{7}$. Thus, EVA has a wide spectrum of industrial applications, such as solar cell encapsulant ${ }^{8}$, foot ware midsole and toy industry.

Besides the common fields mentioned above, bioapplications are also very important to the use of EVA because it is heat processable, commercially available, nontoxic and biocompatible. Hence, it can be used as an antithrombogenic material, as a controlled drug delivery scaffold and as a biomaterial for artificial hearts. However, the non-degradable characteristic of EVA restricts its further bio-applications. Mixing with other biodegradable polymers, such as polyhydroxybutyrate ${ }^{9}$ and polylactide ${ }^{10}$, therefore, maybe an efficient way to endow EVA-based materials with biodegradable to some extent. In the current study, EVA was melt mixed with a biodegradable polymer, Poly ( $\varepsilon$-caprolactone) [PCL], to obtain a new blend biomaterial.

Good thermal conductivity is an important property for polymer composites in practical applications. Different methods have been used to improve the thermal conductivity of polymeric materials. The most commonly used method to 
produce a thermally conductive composite is by adding high thermally conductive fillers. To mention the few, aluminium nitride, carbon nanotubes (CNTs), and boron nitride were normally used to form thermally conductivity composites ${ }^{11-14}$. Carbon based materials, more especially expanded graphite have been used to enhance the heat transfer of polymers, since they have good thermal conductivity and low bulk density ${ }^{15}$. Polymer/EG composites are used in aerospace and sporting goods applications. Electroconductive polymeric composites are mostly employed as heating elements, temperature-dependent resistors and sensors, self-limiting electrical heaters and switching devices ${ }^{16}$.

A lot of studies have been done on the influence of organo-clay on polymer blends ${ }^{17-21}$. These studies have shown the organoclay may reside preferable within the bulk of the better compatible polymer, might also become localized at the interfacial region as well. The interfacial tension is reduced, the droplets coalescence is inhibited and finer dispersion is obtained. Gelfer et al. ${ }^{21}$ reported the reduction in particle size of the dispersed phase of the PS/PMMA blends with the presence of organo-modified montmorillonite (OMMT). It was further mentioned by Voulgaris and coworker ${ }^{18}$ in their study that the presence of OMMT played the role of an emulsifier in PS/PMMA system and showed that this phenomenon increases the melt viscosity of the blend.

In this work, the synergistic effect of EG and Cloisite $15 \mathrm{~A}$ on the thermo mechanical and thermal conductivity properties of EVA/PCL blend has been investigated. It is clear in the latest literature that there is a limited or no information investigating the thermal conductivity and thermo mechanical properties of EVA/PCL blend specifically.

\section{Experimental}

\subsection{Materials}

EVA-460 was manufactured and supplied in granule form by DuPont Packaging and Industrial polymers. EVA-460 contains 18 . wt $\%$ by weight of vinyl acetate (VA) with a BHT antioxidant thermal stabilizer. It has an MFI $\left(190^{\circ} \mathrm{C} 2.16 \mathrm{~kg}^{-1}\right)$ of $2.5 \mathrm{~g} 10$ $\mathrm{min}^{-1}$ (ASTM D 1238-ISO 1133), $\mathrm{T}_{\mathrm{m}}$ of $88^{\circ} \mathrm{C}$, and density of $0.941 \mathrm{~g} \mathrm{~cm}^{-3}$. Expandable graphite ES 250 B5 was supplied by Qingdao Kropfmuehl Graphite (Hauzenberg, Germany). The $\mathrm{Capa}^{\mathrm{TM}} 6500$ polycaprolactone (PCL) was purchased from Southern Chemicals in Johannesburg, South Africa. It has a density of $1.1 \mathrm{~g} \mathrm{~cm}^{-3}$, a glass transition temperature of $-61^{\circ} \mathrm{C}$, a melting temperature of $\sim 60^{\circ} \mathrm{C}$, and a degree of crystallinity of $35 \%$. Cloisite $15 \mathrm{~A}(\mathrm{C} 15 \mathrm{~A})$ was supplied as a cream white powder by Southern Clay Products Inc. (Texas, USA).

\subsection{Preparation of expanded graphite}

The expandable graphite was first dried in an oven at $60{ }^{\circ} \mathrm{C}$ for $10 \mathrm{~h}$ and heated in a furnace at $600{ }^{\circ} \mathrm{C}$ using a glass beaker and maintained at that temperature for $15 \mathrm{~min}$ to form expanded graphite.

\subsection{Preparation of blend and composite samples}

All the samples were prepared by a melt mixing process using a Brabender Plastograph $50 \mathrm{~mL}$ internal mixer at 130 ${ }^{\circ} \mathrm{C}$ and $60 \mathrm{rpm}$ for $20 \mathrm{~min}$. The EVA/PLC blend was kept at (70/30) while varying the expanded graphite content in the range of 0 to $15 \mathrm{phr}$ whereas the $\mathrm{C} 15 \mathrm{~A}$ was kept constant at $3 \mathrm{phr}$. For the blend, the dry components were physically premixed and then fed into the heated mixer, whereas for the composites, the EG and C15A was added into the Brabender mixing chamber within 5 minutes after adding the EVA/PCL blend. The samples were then melt-pressed at $110{ }^{\circ} \mathrm{C}$ for 5 minutes under $50 \mathrm{kPa}$ using a custom built 20 ton hydraulic melt press to form $15 \times 15 \mathrm{~cm}^{2}$ sheets.

\subsection{Sample analysis}

To determine the morphology of the cryofractured surfaces, a TESCAN VEGA 3 scanning electron microscope was used and the analysis was done at room temperature. The samples were gold coated by sputtering to produce conductive coatings onto the samples. Thermogravimetric (TGA) analyses were carried out in a Perkin Elmer Pyris-1 thermogravimetric analyzer. Samples ranging between 5 and $10 \mathrm{mg}$ were heated from 30 to $650^{\circ} \mathrm{C}$ at a heating rate of 10 ${ }^{\circ} \mathrm{C} \mathrm{m^{-1 }}$ under nitrogen (flow rate $20 \mathrm{~mL} \mathrm{~min}^{-1}$ ). Thermal conductivity measurements were performed on discs $5 \mathrm{~mm}$ thick and $12 \mathrm{~mm}$ in a diameter using a ThermTest Inc. The Hot disk 500 thermal constants analyzer which uses the transient plane source method was employed. A $3.2 \mathrm{~mm}$ Kapton disk type sensor was selected for the analysis. The sensor was sandwiched between two sample discs. Three measurements were performed for each composition. Dynamic mechanical analysis were performed from -90 to $90{ }^{\circ} \mathrm{C}$ in bending (dual cantilever) mode at a heating rate of $3{ }^{\circ} \mathrm{C}$ $\min ^{-1}$ and a frequency of $1 \mathrm{~Hz}$. The crystalline structures of EG and Cloisite 15A were determined through X-ray diffraction (XRD). A D8 Advance diffractometer (BRUKER AXS, Germany) with PSD Vantec-1 detectors and $\mathrm{Cu} \mathrm{K}_{\alpha}$ radiation $(\lambda=1.5406)$, a tube voltage of $40 \mathrm{kV}$, a current of $40 \mathrm{~mA}$ and a V20 slit were used.

\section{Results and Discussion}

\subsection{Scanning electron microscopy (SEM)}

The morphology of expandable (a) and expanded (b) graphite are shown in Figure 1, and its composites were presented by in Figure 2. Expandable graphite appeared as loose rigid flakes with random shapes and sizes ranging from approximately 500 to $1000 \mu \mathrm{m}$, whereas expanded graphite appeared as spongy attached 


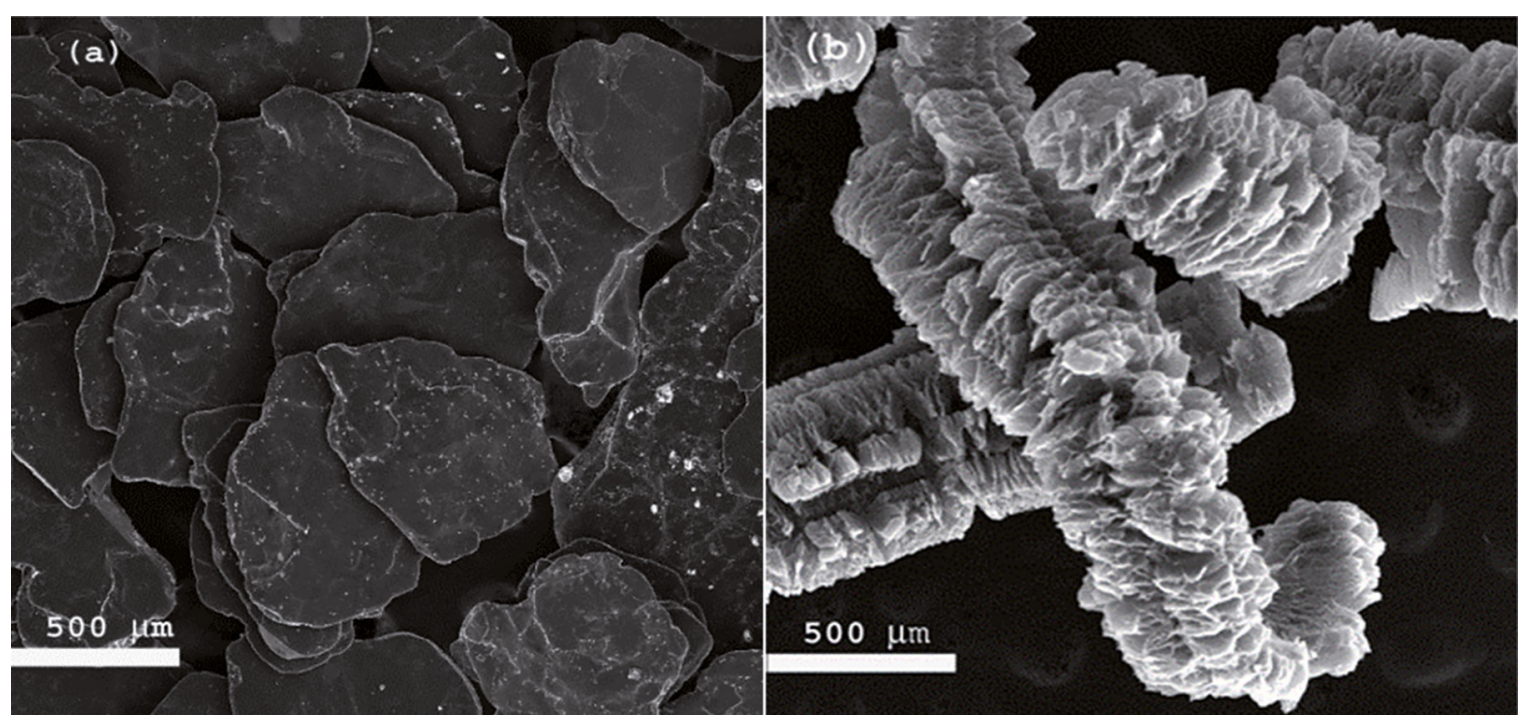

Figure 1: SEM micrographs of a) Expandable, b) Expanded graphite
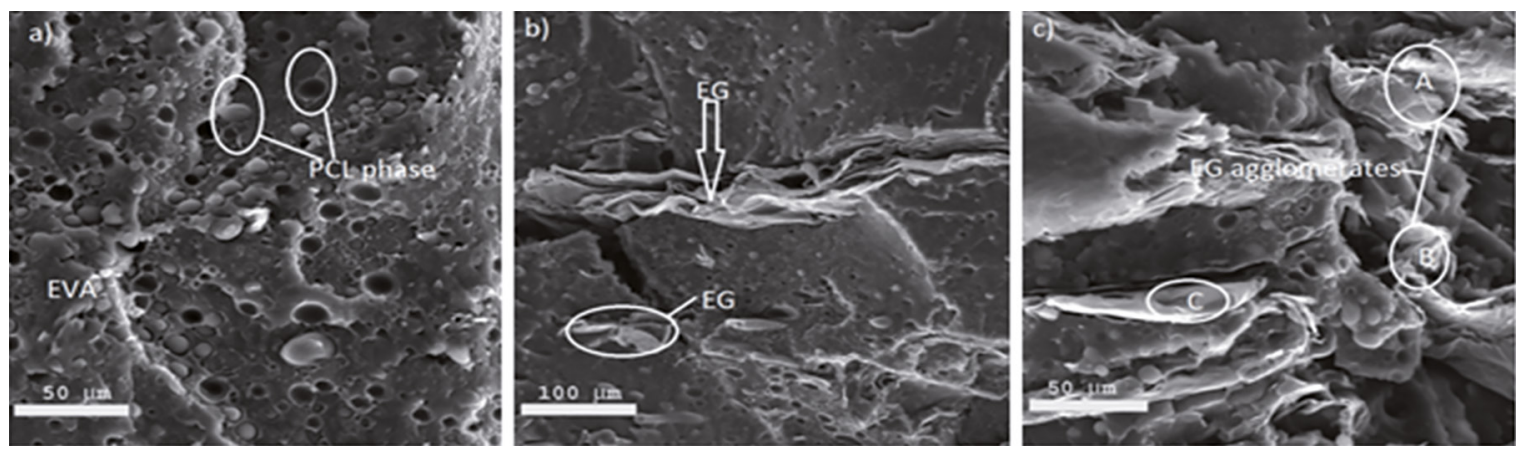

Figure 2: Unetched scanning electron micrographs of a) EVA/PCL blend , b) 70/30 w/w EVA/PCL+ 5phr EG and (c) 70/30 w/w EVA/ PCL+ 15phr EG.

flakes protruding like a scaled worm. The size of the attached flakes is around 10 to $50 \mu \mathrm{m}$. This observation is in line with the fact that carbon atoms of expandable graphite are covalently bonded to each other in a hexagonal arrangement by weak Van der Waals forces, which breakdown at higher temperatures to the voluminous expansion along the c-axis direction in more than 100 times its original size, and covering the entire burning surface by "worm-like" structure with air gaps ${ }^{22,23}$.

The microstructures of the unetched blend and composites are shown in the SEM migrographs (Figure 2). It is apparent from the micrographs that the blend had a phase separated morphology, in which the PCL droplets were dispersed uniformly in the continuous EVA matrix (Figure 2(a)). It is clear from Figure 2 (b) that the 5 phr of EG showed a slight agglomeration inside the EVA/PCL blend, wheares Figure 2(c) indicated larger agglomeration, which is in line with the increased EG content. This suggested that particle-particle interaction dominated polymer-particle interaction and intensified with the content ${ }^{24}$.

Figures 3 shows phase morphologies (etched) observed by SEM for the EVA/PCL blend, 70/30 w/w EVA/PCL+ 5phr EG and (70/30 w/w EVA/PCL +5 phrEG) +3 phrClay composites. In order to differentiate PCL phase from the EVA phase, the samples were etched by acetic acid to remove PCL in the cross section. All samples showed droplet-matrix morphologies comprised of PCL domains dispersed in an EVA matrix; the dark holes or etched phase correspond to the PCL domains that have been etched by the solvent. The presence of both EG and Cloisite $15 \mathrm{~A}$ reduced the size of the minor phase from approximately $10 \pm 2 \mu \mathrm{m}$ to $5 \pm 1 \mu \mathrm{m}$. It is seen in Figure 3 (b) and (c) that EG forms agglomerates, however Cloisite 15A is not clear from Figure 3(c). This is possibly caused by the interaction between polar vinyl acetate (VA) groups in the EVA chains and the organic modifier in the clay ${ }^{25}$.

\subsection{X-ray diffraction (XRD)}

Figure $4(a$ and $b$ ) represents x-ray patterns of EG, Clay, PCL, EVA and EVA/PCL blend. The $2 \theta$ values, the corresponding $\mathrm{d}$-spacing and crystallinity index of each 

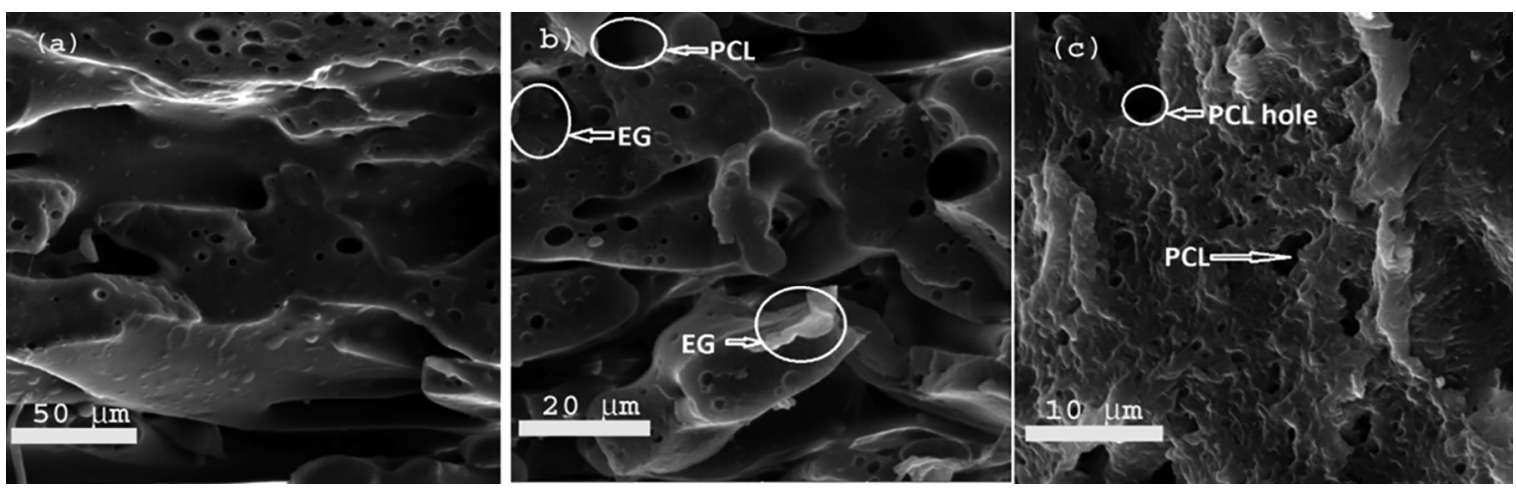

Figure 3: Etched scanning electron micrographs of a) EVA/PCL blend, b) 70/30 w/w EVA/PCL+ 5phr EG and (c) 70/30 w/w EVA/PCL+ 5 phrEG)+3phrClay
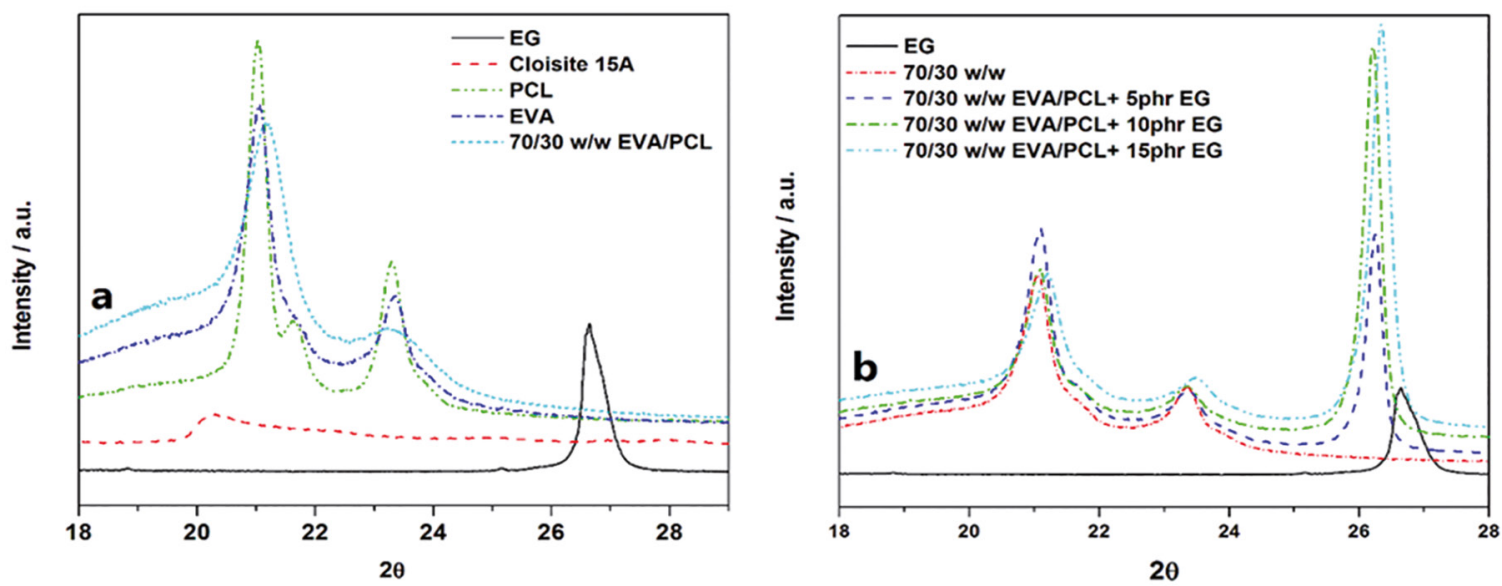

Figure 4: X-ray diffraction patterns of (a) pure materials and (b) blend composites

material were tabulated in Table 1 . The average size of the $d$ - or basal spacing $\left(d_{200}\right)$, which is the sum of the layer and interlayer distances between the EG platelets and composites, was determined from the $2 \theta$ position of the $\left(d_{200}\right)$ diffraction peak of each material using Bragg's law (equation 1) and tabulated in Table 1.

$$
\begin{aligned}
& \mathrm{n} \lambda=2 d \sin \theta \\
& \text { where } \mathrm{n}=1 \text { and } \\
& \lambda=1.54056 \AA
\end{aligned}
$$

where $\mathrm{n}$ is a positive integer and $\lambda$ is the wavelength of incident wave, $\AA$ is Angstrom. The crystallinity index (CI) was determined using the peak height method: In this method CI is calculated from the height of the 200 peak $\left(\mathrm{I}_{200}\right)$ and the height of the minimum $\left(\mathrm{I}_{\mathrm{AM}}\right)$ between the 110 peak and the 200 peaks. EG has shown distance between successive carbon layers at $0.34 \mathrm{~nm}$ and diffraction peak at $26.7^{\circ}$, which attributed to the stacking of single graphene layers ${ }^{26}$. Van der Waals interaction among thousands of the clay platelets resulted into a halo peak at $20.0^{\circ}$. EVA and the blend largely shown a weak Bragg reflections at around 21 and $23^{\circ}$, corresponding to (110) and (200), in their diffraction diagrams which are drowned by the strong and dominant amorphous halo. PCL contains three strong reflections at about $21.4,22.0$ and $23.7^{\circ}$, corresponding to the (110), (111) and (200) planes of the orthorhombic crystal structure respectively ${ }^{25-27}$.

The presence of EG in the blend led to a narrow third diffraction peak at $26.1^{\circ}$ which clearly intensify relative to the EG concentration (Figure $4 \mathrm{a}$ and $\mathrm{b}$ ). The appearance of this sharp peak suggests that not all of the graphite sheets were dispersed in EVA/PCL blend. The values in Table 1 show that there was no change in the d-spacing of graphite in the EVA/PCL/EG system. This further indicates that the graphite platelets were in order and multilayer, and the processing technique used in this study had negligible effect, if not whatsoever, on the structure of the graphite platelets. The presence of clay in the blend composites slightly decreased the crystallinity index of all the blend composites, and $d$ spacing has decreased indirectly proportional to the clay content as indicated 
Table 1: Crystallinity index and Basal spacings of the EG in the samples.

\begin{tabular}{lccc}
\hline Sample & $2 \theta$ (Main reflection) & $\mathrm{d}_{002} / \mathrm{nm}$ & Crystallinity index (\%) \\
\hline EG & 26.7 & 0.34 & 60 \\
Cloisite 15A & 20 & - & 32 \\
PCL & 21.4 & - & 71 \\
EVA & 21 & - & 58 \\
EVA/PCL blend & 21 & 0.34 & 47 \\
$70 / 30$ w/w EVA/PCL+ 5phr EG & 26.3 & 0.35 & 74 \\
$70 / 30$ w/w EVA/PCL+ 10phr EG & 26.4 & 0.35 & 82 \\
$70 / 30$ w/w EVA/PCL+ 15phr EG & 26.2 & 0.35 & 80 \\
$70 / 30$ w/w EVA/PCL+ 5phrEG)+3phrClay & 27.1 & 0.34 & 69 \\
$70 / 30$ w/w EVA/PCL+ 10phrEG)+3phrClay & 26.5 & 0.35 & 71 \\
$70 / 30$ w/w EVA/PCL+15phrEG)+3phrClay & 26.2 & 0.35 & 79 \\
\hline
\end{tabular}

by a clear shift of reflection peak of composites to higher angles. This is more pronounced into 5 and $10 \mathrm{phr}$ EG containing blend composites (Figure 5). It is well known that the stronger the intensity of the diffraction peak, the higher the degree of graphite stacking and the worse the exfoliation and the dispersion of graphite ${ }^{28}$. As a result and in line with SEM results it can be suggested in Figure 4b and 5 that at lower graphite content ( $5 \mathrm{phr}$ ) that the graphite disperses more uniformly with smaller agglomerates in both clay containing and non-clay samples. With the increase of graphite content, graphite sheets increase, leading to a high probability of re-stacking and poor dispersion as well. It is worth pointing out that similar results have been previously reported in other polymer matrices containing graphite ${ }^{26,28}$. In this study the presence of the clay to the system seems to have changed the crystalline structure of the system which ultimately rendered a decrease in a $d$ spacing. This is possibly caused by the interaction between polar vinyl acetate (VA) groups in the EVA chains and the organic modifier in the clay which caused unclear clay tactoids in $\mathrm{SEM}^{25}$.

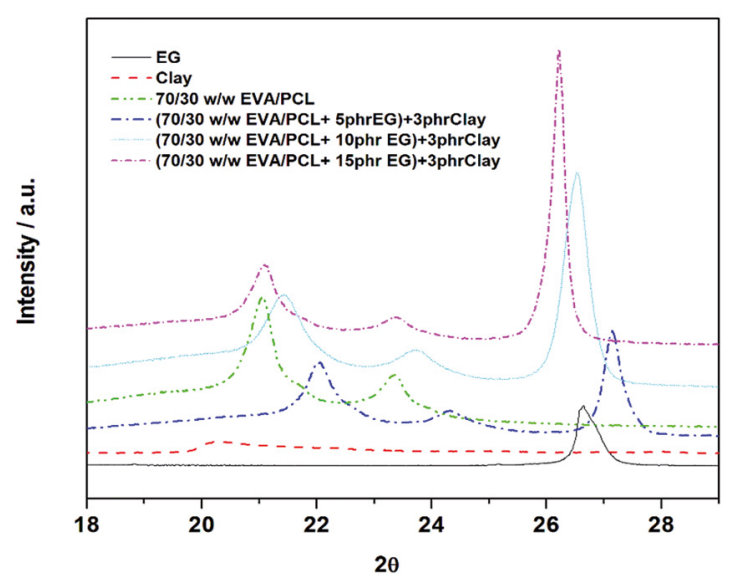

Figure 5: X-ray diffraction patterns of blend composites with clay

\subsection{Thermogravimetric analysis}

Figure 6 represents TGA and DTG thermograms of EG, Clay, PCL, EVA and EVA/PCL blend. Generally, graphene sheets exhibits very high thermal stability with little or no weight loss up to $650{ }^{\circ} \mathrm{C}$. Hofmann elimination reaction resulted into decomposition of the intercalated organic ammonium salts of Cloisite $15 \mathrm{~A}$, which shows a mass loss of almost $40 \%$ in the temperature range $200-400{ }^{\circ} \mathrm{C}^{30}$. EVA shows two-step degradation related to deacetylation and main-chain decomposition ${ }^{29}$, while the PCL degrades in a single stage (around 390 to $400^{\circ} \mathrm{C}$ ) involving simultaneous occurrence of two types of reactions; random chain scission and unzipping from hydroxyl end leading to the formation of $\varepsilon$-caprolactone. The EVA/PCL blend shows three degradation steps with intermediatory thermal stability which are related to the degradation of the two polymers. Unexpectedly, the blend showed the char content greater than of the two individual polymers. However, considering that EVA thermally degrades into evolution of acetic acid and C-C and $\mathrm{C}-\mathrm{H}$ chain scission, while $\mathrm{PCL}$ releases 5-hexenioc acid, $\mathrm{CO}_{2}, \mathrm{CO}$ and $\varepsilon$-caprolactone, it is possible that interactions of free radicals, the acids and ketone formed a crosslinked structure to increase the $\mathrm{char}^{7,35,36}$. On the other hand, Moura et al. ${ }^{37}$, suggested that the percentage of acetic acid in EVA and molar masses of both polymers could be liable for the observation.

Figure 7 and 8 depict the TGA and DTG curves of EVA/ PCL blend, clay containing samples and non-clay containing samples. Thermal degradation temperatures at $20 \%$ and $80 \%$ weight loss are given in Table 2. The thermal stability of the EG composites slightly improved by the incorporation of EG, compared with EVA/PCL blend. For instance, the thermal degradation temperatures for $20 \%$ and $80 \%$ weight loss of the EVA/PCL blend are 399 and $469^{\circ} \mathrm{C}$, while for the composite with $15 \mathrm{phr}$ EG; there was an increase of 406 and $491^{\circ} \mathrm{C}$, respectively. This distinct improvement in the thermal stability of the composites was associated with 

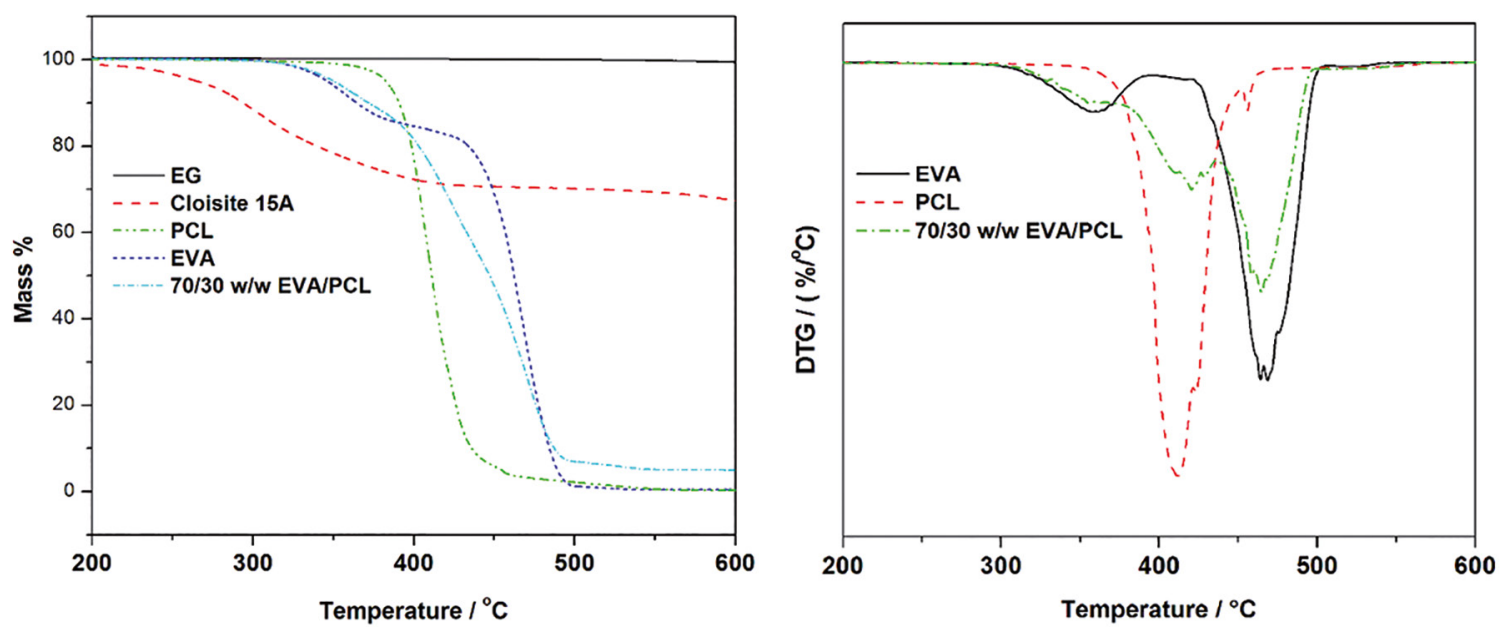

Figure 6: TGA of EG, Cloisite 15A, EVA as well as PCL and DTG curves
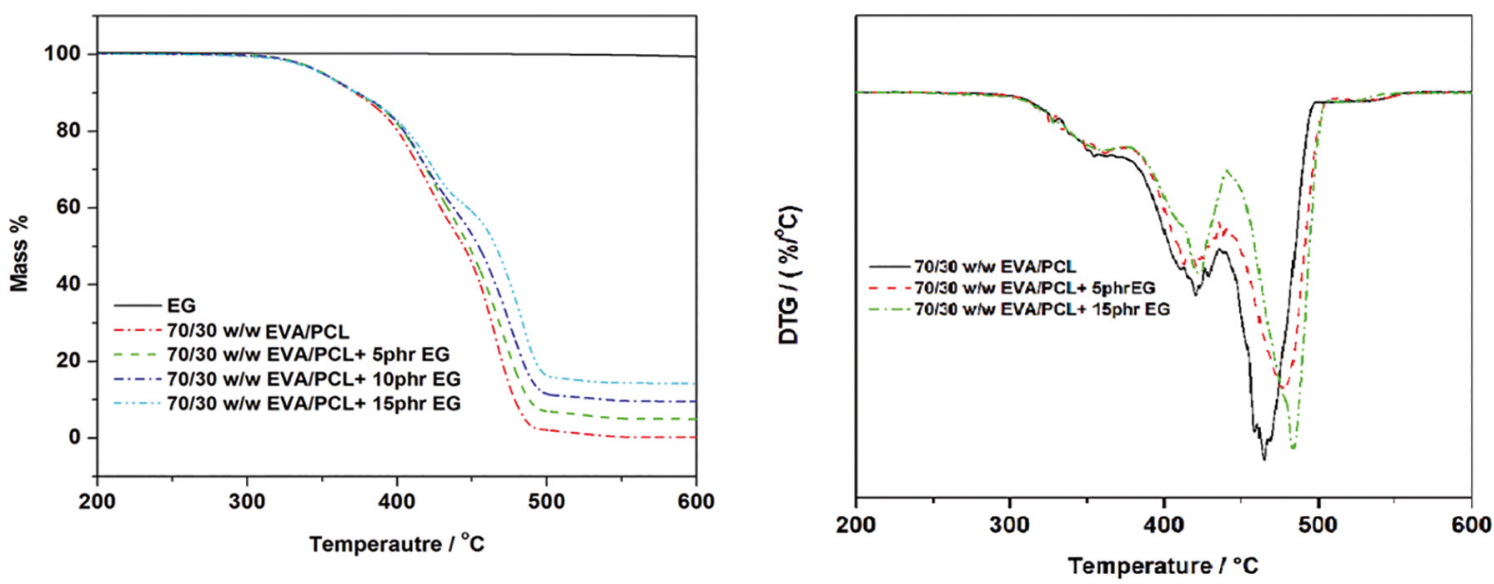

Figure 7: TGA and DTG curves of EVA/PCL blend and EVA/PCL blend with different content of EG
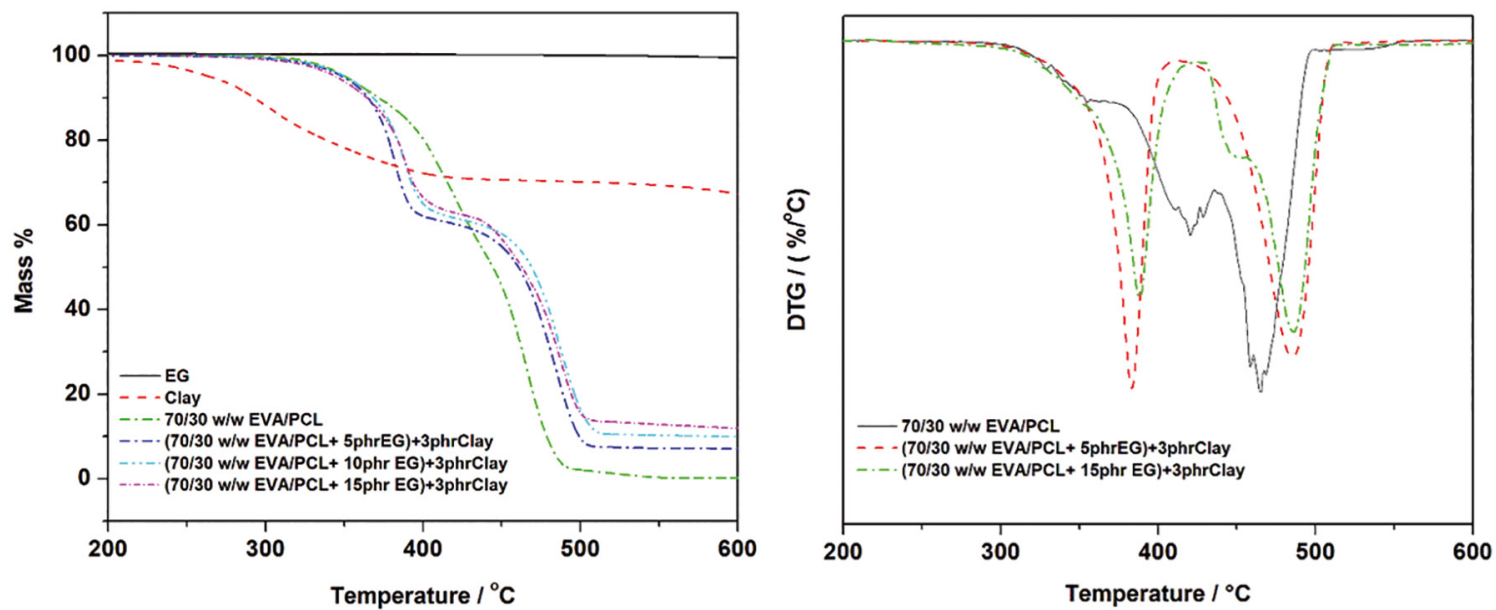

Figure 8: TGA and DTG curves of EVA/PCL blend and EVA/PCL blend with different content of EG in the presence of clay 
Table 2: Degradation temperatures at 20 and $80 \%$ mass for all the investigated samples.

\begin{tabular}{lcc}
\hline Sample & $\mathrm{T}_{20 \%}\left({ }^{\circ} \mathrm{C}\right)$ & $\mathrm{T}_{80 \%}\left({ }^{\circ} \mathrm{C}\right)$ \\
\hline EVA & 432 & 475 \\
PCL & 401 & 427 \\
70/30 w/w EVA/PCL & 399 & 469 \\
70/30 w/w EVA/PCL+ 5phr EG & 401 & 476 \\
70/30 w/w EVA/PCL+ 10phr EG & 404 & 480 \\
70/30 w/w EVA/PCL+ 15phr EG & 406 & 491 \\
70/30 w/w EVA/PCL+ 5phrEG)+3phrClay & 377 & 487 \\
70/30 w/w EVA/PCL+ 10phrEG)+3phrClay & 385 & 493 \\
70/30 w/w EVA/PCL+ 15phrEG)+3phrClay & 383 & 493 \\
\hline
\end{tabular}

the 2-dimensional-planar structure of the EG in the EVA/ PCL blend, which served as a barrier preventing the further degradation of the underlying EVA/PCL blend. Similar results were obtained by Murariu et al. ${ }^{26}$, who investigated the production and properties of polylactide composites filled with expanded graphite. They reported that the addition of $\mathrm{EG}$, for an example $12 \% \mathrm{EG}$ leads to an increase by $10^{\circ} \mathrm{C}$ of the $5 \%$ and $50 \%$ weight loss. This was attributed to the shielding effect conferred by flake-like nanofiller. In fact, the layers of EG are thought to increase the diffusion pathway of the degradation by -products and the good thermal stability was associated to hindered diffusion of volatile decomposition products. It is interesting to observe in Figure 8 that the presence of $3 \mathrm{phr}$ of clay accelerated the deacetylation of EVA and degradation of PCL respectively. However, above $450^{\circ} \mathrm{C}$ the synergy of EG and clay revealed the highest thermal stability compared to the rest. The acceleration of thermal degradation before $450^{\circ} \mathrm{C}$ might be due to the products of the decomposition of the alkylammonium cations catalyzing the degradation of the polymer matrices ${ }^{30}$. The elimination of the ammonium modifier apparently results in a substitution of the ammonium linkage on the clay with a hydrogen proton due to $\beta$-carbon fracture, which acts as a Br$\theta$ nsted acidic site to accelerate the polymer degradation. Eventually, the $\alpha$-olefins, by products or intermediates produced in this reaction could attack the polymer and promote polymer degradation. Beyond $450^{\circ} \mathrm{C}$ the platelets of the two fillers probably formed barricades to delay the diffusion of volatiles or more thermally stable intermediates were formed to render the observed thermal stability. The observations and the fact that there is a significant increase in char content for all blend composites suggest that the materials, especially those containing clay are ideal for flammability retardance applications.

\subsection{Dynamic mechanical properties}

Figure $9(\mathrm{a}$ and $\mathrm{b})$ revealed the temperature dependence of the storage modulus as well as loss modulus of the EVA/
PCL blend, non-clay and clay containing samples. It can be seen that the storage modulus of EVA/PCL blend generally increases with the addition of EG and Cloisite 15A. The storage and loss moduli are high for lower graphite content in both the clay and non-clay containing samples compared to the blend. A better dispersion of graphene sheets at lower content throughout the blend matrix, as suggested by SEM, is responsible for the observation. It is understood that the less agglomeration of EG in the matrix could enhance the interfacial factors, which could contribute to the stiffening effect for the composites ${ }^{31}$. However in this study clay was added, from which the synergy indicated a better ability to restrict molecular motions which yielded the highest modulus compared to the rest. Furthermore, as the EG and Cloisite $15 \mathrm{~A}$ are filled in the blend matrix, the synergy of both fillers could further reduce and restrict molecular motion. Similar results were obtained by Pedrazzoli and co-authors ${ }^{32}$, who investigated the synergistic effect of exfoliated graphite nanoplatelets and short glass fiber on the mechanical and interfacial properties of epoxy composites. They reported that both fillers (GNP and GF) could reduce and restrict molecular motions and thus enhance the restriction on the rate of relaxation.

In both the loss factor and storage modulus three relaxations are observed. The small loss peak was located at a temperature between -50 and $-40{ }^{\circ} \mathrm{C}$ and it is more evident in the EVA/PCL blend. This is attributed to the glass transition temperature of the poly (caprolactone). EVA/PCL blend and their composites with EG as well Cloisite $15 \mathrm{~A}$ show a $\beta$-relaxation between -40 and $0{ }^{\circ} \mathrm{C}$. The $\beta$-relaxation is attributed to the motion of chain segments of three or four methylene $\left(-\mathrm{CH}_{2}\right)$ groups in the amorphous phase $\mathrm{e}^{33}$, and is known as the glass transition $\left(\mathrm{T}_{\mathrm{g}}\right)$ of EVA. The transition between around $60^{\circ} \mathrm{C}$ in the curves of the EVA/PCL blend and all composites is the result of the melting of the PCL in the blend and composite. It is clear that there is a slight shift in glass transition for all composites compared to the blend which, in a way, confirms the alleged restriction of molecular motions by the synergy of the fillers.

\subsection{Thermal conductivity}

Thermal conductivity of EVA/PCL blend, EG EVA/PCL blend composites are represented in Figure 10. It is well known that the phonon transport is the main mechanism of heat conduction in most EG polymer composites ${ }^{34}$. Phonons transfer heat energy through interactions with each other and with subatomic particles. Lattice imperfections such as dislocations, voids and impurities can introduce anharmonicities which result in phonon scattering. In a multi-phase system such as polymeric composites scattering also occurs when phonons propagate through a boundary which separates one phase from another. All blend composites revealed a significant increase in 

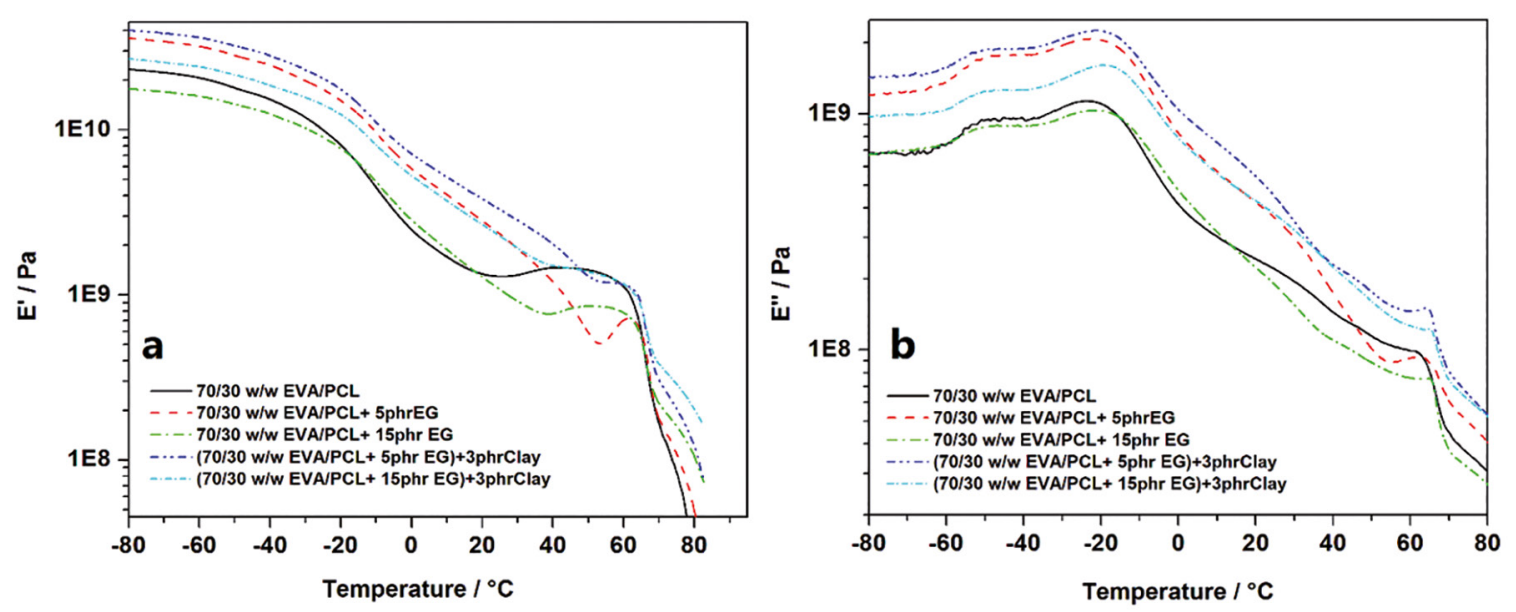

Figure 9: Storage and Loss modulus as function of temperature for EVA/PCL blend, EVA/PCL/EG and EVA/PCL/EG/Cloisite 15A composites

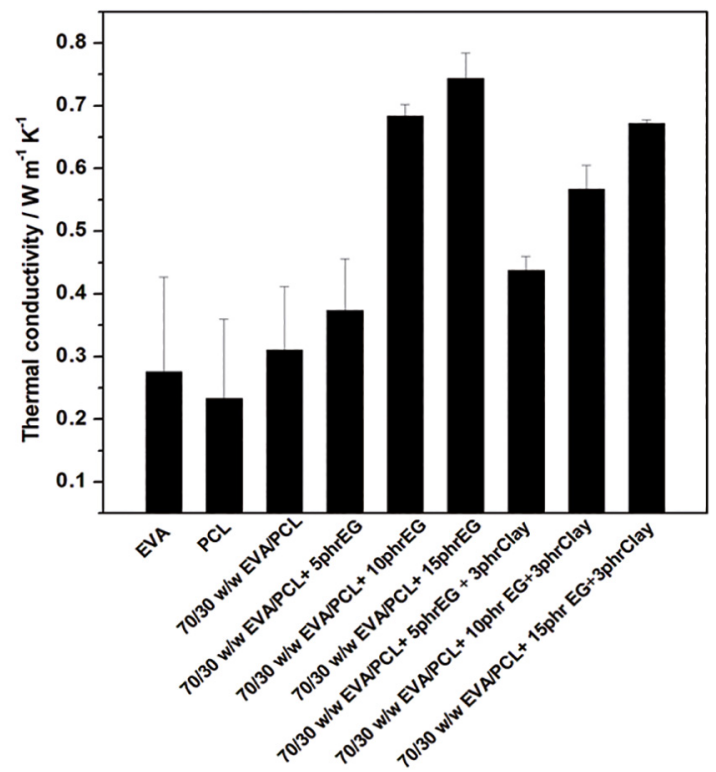

Figure 10: Thermal conductivities of EVA/PCL blend and different blend composites

thermal conductivity which increased steadily with the concentration of EG, though the clay containing composites are somewhat lower compared to the EG counterparts. Possible explanations for the observation may either be thermal conductivity of fillers and/or interaction between them. As the filler content increases, (in this case EG), the percolation maintained where the mean interparticle distance would be smaller than in other parts, leading to a high thermal conductivity along percolates. Microfillers with high thermal conductivity and high filler content can increase the heat transfer rate as heat conduction mainly occurs through them. In the case of the clay containing composites, it is clear that non-conductive sheets of the clay somehow increased defects and/or likely acted as a barrier to the phonon transport amongst the EG particles, which hindered conductive networks. It is clear that the observations resulted from change in crystalline structures and orientations of the fillers as confirmed by SEM and XRD. Therefore, it is possible to presume that below $450^{\circ} \mathrm{C}$ a mechanism of scattering of phonons could also be responsible for the steep decline in thermal stability.

\section{Conclusions}

In this work, the synergistic effect of EG and C15A on the thermomechanical and thermal conductivity properties of EVA/PCL blend was investigated. SEM and XRD showed that as the graphite loading level increases, the probability of graphite re-stacking increases, resulting in poor graphite dispersion. Graphite has an inherent tendency to form agglomerates due to strong Van der Waals attraction, large surface areas and $\pi-\pi$ interaction. The dynamic mechanical analysis showed an increase in the storage modulus for the composite containing low content of EG (5phr) in both the non-clay and clay containing samples. The less agglomeration of EG in the matrix enhanced interfacial factors as a result improved the stiffening effect of the EVA/ PCL blend. Furthermore, the synergistic effect of the less agglomerated EG (5phr) and C15A could further reduce and restrict molecular motion resulting in higher storage modulus than EG. The addition and increase of EG content gives rise in thermal conductivity of the EVA/PCL blend in both the clay containing and non-clay containing samples compared to EVA/PCL blend. However, in the thermal conductivity results the clay containing samples showed less values compared to the samples EG blend composites. All observations provoked a study of thermal degradation kinetics of all investigated samples in order to draw a line between the effects of the defects and hindrance of phonons by clay platelets. 


\section{Acknowledgements}

Mokgaotsa Mochane would like to acknowledge the University of Zululand with SEM and XRD. Also the collaboration with University of the Free State (QwaQwa) for some equipment. Opinions expressed and conclusions arrived at, are those of the author and are not necessarily to be attributed to the institutions.

\section{References}

1. Canto LB. On the coarsening of the phase morphology of PP/ EVA blends during compounding in a twin screw extruder. Polymer Testing. 2014;34:175-182.

2. Jayanarayanan K, Thomas S, Joseph K. Morphology, static and dynamic mechanical properties of in situ microfibrillar composites based on polypropylene/poly (ethylene terephthalate) blends. Composites Part A: Applied Science and Manufacturing. 2008;39(2):164-175.

3. Yu L, Dean K, Li L. Polymer blends and composites from renewable resources. Progress in Polymer Science. 2006;31(6):576-602.

4. Si X, Guo L, Guo L, Wang Y, Lau KT. Preparation and study of polypropylene/polyethylene terephthalate composite fibres. Composites Science and Technology. 2008;68(14):2943-2947.

5. Huerta-Martínez BM, Ramírez-Vargas E, Medellín-Rodríguez FJ, García RC. Compatibility mechanisms between EVA and complex impact heterophasic PP-EP $x$ copolymers as a function of EP content. European Polymer Journal. 2005;41(3):519-525.

6. Sivalingam G, Karthik R, Madras G. Blends of poly( $(\varepsilon-$ caprolactone) and poly(vinyl acetate): mechanical properties and thermal degradation. Polymer Degradation and Stability. 2004;84(2):345-351.

7. Wu D, Zhang J, Zhou W, Yao Z, Zhang M, Lin D, et al. Morphological control of porous ethylene-vinyl acetate copolymer membrane obtained from a co-continuous ethylene-vinyl acetate copolymer/poly ( $€$-caprolactone) blend. Polymer International. 2014;63(3):470-478.

8. Stark W, Jaunich M, Bohmeyer W, Lange K. Investigation of the crosslinking behaviour of ethylene vinyl acetate (EVA) for solar cell encapsulation by rheology and ultrasound. Polymer Testing. 2012;31(7):904-908.

9. Kim MN, Lee AR, Lee KH, Chin IJ, Yoon JS. Biodegradability of poly(3-hydroxybutyrate) blended with poly(ethylene-co-vinyl acetate) or poly(ethylene oxide). European Polymer Journal. 1999;35(6):1153-1158.

10. Moura I, Botelho G, Machado AV. Characterization of EVA/PLA Blends When Exposed to Different Environments. Journal of Polymers and the Environment. 2014;22(1):148-157.

11. Zhou Y, Wang H, Wang L, Yu K, Lin Z, He L, et al. Fabrication and characterization of aluminum nitride polymer matrix composites with high thermal conductivity and low dielectric constant for electronic packaging. Materials Science and Engineering: B. 2012;177(11):892-896.
12. Xu Y, Chung DDL, Mroz L. Thermally conducting aluminum nitride polymer-matrix composites. Composites Part A: Applied Science and Manufacturing. 2001;32(12):1749-1757.

13. Mazov IN, Llinykh IA, Kuznetsov VL, Stepashkin AA, Ergin KS, Muratov DS, et al. Thermal conductivity of polypropylenebased composites with multiwall carbon nanotubes with different diameter and morphology. Journal of Alloys and Compounds. 2014;586(Suppl 1):S440-S442.

14. Mhike W, Focke WW, Mofokeng JP, Luyt AS. Thermally conductive phase-change materials for energy storage based on low-density polyethylene, soft Fischer-Tropsch wax and graphite. Thermochimica Acta. 2012;527:75-82.

15. Karaipekli A, Sari A, Kaygusuz K. Thermal conductivity improvement of stearic acid using expanded graphite and carbon fiber for energy storage applications. Renewable Energy. 2007;32(13):2201-2210.

16. Krupa I, Novák I, Chodák I. Electrically and thermally conductive polyethylene/graphite composites and their mechanical properties. Synthetic Metals. 2004;145(2-3):245-252.

17. Filippi S, Dintcheva NT, Scaffaro R, La Mantia FP, Polacco G, Magagnini P. Effects of organoclay on morphology and properties of nanocomposites based on LDPE/PA-6 blends without and with SEBS-g-MA compatibilizer. Polymer Engineering \& Science. 2009;49(6):1187-1197.

18. Voulgaris D, Petridis D. Emulsifying effect of dimethyldioctadecylammonium-hectorite in polystyrene/ poly(ethyl methacrylate) blends. Polymer. 2002;43(8):2213-2218.

19. Wang Y, Zhang Q, Fu Q. Compatibilization of Immiscible Poly(propylene)/Polystyrene Blends Using Clay. Macromolecular Rapid Communications. 2003;24(3):231-235.

20. Khatua BB, Lee DJ, Kim HY, Kim JK. Effect of Organoclay Platelets on Morphology of Nylon-6 and Poly(ethylene-ranpropylene) Rubber Blends. Macromolecules. 2004;37(7):2454-2459.

21. Gelfer MY, Song HH, Liu L, Hsiao BS, Chu B, Rafailovich $\mathrm{M}$, et al. Effects of organoclays on morphology and thermal and rheological properties of polystyrene and poly(methyl methacrylate) blends. Journal of Polymer Science Part A: Polymer Chemistry. 2003;41(1):44-54.

22. Sun Z, Ma Y, Xu Y, Chen X, Chen M, Yu J, et al. Effect of the particle size of expandable graphite on the thermal stability, flammability, and mechanical properties of high-density polyethylene/ ethylene vinyl-acetate/expandable graphite composites. Polymer Engineering and Science. 2014;54(5):1162-1169.

23. Zhao YF, Xiao M, Wang SJ, Ge XC, Meng YZ. Preparation and properties of electrically conductive PPS/expanded graphite nanocomposites. Composites Science and Technology. 2007;67(11-12):2528-2534.

24. Chu K, Jia C. Enhanced strength in bulk graphene-copper composites. Physica Status Solidi A. 2014;211(1):184-190.

25. Cai Y, Song L, He Q, Yang D, Hu Y. Preparation, thermal and flammability properties of a novel form-stable phase change materials based on high density polyethylene/poly(ethylene-covinyl acetate)/organophilic montmorillonite nanocomposites/ paraffin compounds. Energy Conversion and Management. 2008;49(8):2055-2062. 
26. Murariu M, Dechief AL, Bonnaud L, Paint Y, Gallos A, Fontaine $\mathrm{G}$, et al. The production and properties of polylactide composites filled with expanded graphite. Polymer Degradation and Stability. 2010;95(5):889-900.

27. Ciardelli G, Chiono V, Vozzi G, Pracella M, Ahluwalia A, Barbani $\mathrm{N}$, et al. Blends of Poly-( $\varepsilon$-caprolactone) and Polysaccharides in Tissue Engineering Applications Biomacromolecules. 2005;6(4):1961-1976.

28. Wang L, Zhang L, Tian M. Improved polyvinylpyrrolidone (PVP)/graphite nanocomposites by solution compounding and spray drying. Polymers for Advanced Technologies. 2012;23(3):652-659.

29. George JJ, Bhowmick AK. Ethylene vinyl acetate/expanded graphite nanocomposites by solution intercalation: preparation, characterization and properties. Journal of Materials Science. 2008;43(2):702-708.

30. Xu X, Ding Y, Qian Z, Wang F, Wen B, Zhou H, et al. Degradation of poly(ethylene terephthalate)/clay nanocomposites during melt extrusion: Effect of clay catalysis and chain extension. Polymer Degradation and Stability. 2009;94(1):113-123.

31. Hatui G, Bhattacharya P, Sahoo S, Dhibar S, Das CK. Combined effect of expanded graphite and multiwall carbon nanotubes on the thermo mechanical, morphological as well as electrical conductivity of in situ bulk polymerized polystyrene composites. Composites Part A: Applied Science and Manufacturing. 2014;56:181-191.
32. Pedrazzoli D, Pegoretti A, Kalaitzidou K. Synergistic effect of exfoliated graphite nanoplatelets and short glass fiber on the mechanical and interfacial properties of epoxy composites. Composites Science and Technology. 2014;98:15-21.

33. Grigoryeva O, Fainleib A, Starostenko O, Tolstov A, Brostow W. Thermoplastic elastomers from rubber and recycled polyethylene: chemical reactions at interphases for property enhancement. Polymer International. 2004;53(11):1693-1703.

34. Ganguli S, Roy AK, Anderson DP. Improved thermal conductivity for chemically functionalized exfoliated graphite/epoxy composites. Carbon. 2008;46(5):806-817.

35. Wu D, Zhang J, Zhang M, Zhou W, Lin D. The co-continuous morphology of biocompatible ethylene-vinyl acetate copolymers/poly( $\varepsilon$-caprolactone) blend: effect of viscosity ratio and vinyl acetate content. Colloid and Polymer Science. 2011;289(15):1683-1694.

36. Vogel C, Siesler HW. Thermal Degradation of Poly(e-caprolactone), Poly(L-lactic acid) and their Blends with Poly(3-hydroxybutyrate) Studied by TGA/FT-IR Spectroscopy. Macromolecular Symposia. 2008;265(1):183-194.

37. Moura I, Nogueira R, Legare VB, Machado AV. Effect of PCL and EVA Molar Mass on the Development of Sustainable Polymers. Soft Materials. 2014;12(1):88-97. 